\title{
Neuronal intestinal pseudoobstruction
}

INSERM

\section{Source}

INSERM. (1999). Orphanet: an online rare disease and orphan drug data base. Neuronal intestinal pseudoobstruction. ORPHA:99811

Neuronal intestinal pseudoobstruction is a form of chronic intestinal pseudoobstruction caused by a developmental failure of the enteric neurons to differentiate or migrate properly and manifests as a bowel obstruction. 